\title{
Pódio Vexatório: o bronze brasileiro no ranking mundial de países com maior população carcerária e as possíveis estratégias desencarceradoras
}

Tamires Maria Alves

\section{Tamires Maria Alves}

Doutora em Ciência Política pela UFF.

Professora Substituta IRID - UFRJ.

E-mail: tamiresmalves@gmail.com

ORCID: 0000-0002-2608-7015

\section{Resumo}

A acumulação do capital e a desigualdade social por esta engendrada foram responsáveis também pela produção de uma sociedade disciplinadora que identifica sujeitos criminalizáveis de acordo com suas estratégias de controle social. O hiperencarceramento comporta-se como dispositivo disciplinador da massa estigmatizada e perpetua ilusões correcionais ao difundir juízos de que a intervenção penal teria o intuito de reconstruir a identidade do sujeito desviante. Entretanto os dados referentes ao sistema punitivo brasileiro apenas apresentam a seletividade deste. $\mathrm{O}$ objetivo deste trabalho é construir narrativas deslegitimizadoras da prisão ao apontar como esta instituição apenas aprofunda as desigualdades. A teoria abolicionista contribuiu para o debate ao problematizar as práticas punitivistas sociais e fornecer algumas possibilidades para a mudança deste cenário.

\section{Palavras chave}

Encarceramento, Abolicionismo Penal, Penas privativas de liberdade, Criminalização da pobreza, Alternativas penais

\begin{abstract}
The accumulation of capital, and the social inequality derived from it, were also responsible to produce a disciplinary society that identifies criminalizable subjects according to strategies of social control. Hiperincarceration is established as a disciplining device of the stigmatized mass and it perpetuates corrective illusions that criminal intervention has the purpose of reconstructing the identity of the deviant subject. However, data referring to the Brazilian punitive system unveils the selectivity of this system. This paper aims to construct narratives that deslegitimize prison when it points out to the ways in which this institution deepens inequalities. The abolitionist theory contributes to this debate when problematizing the authoritarian society, as well as its punitive practices and shows some possibilities to change this scenario.
\end{abstract}

\section{Keywords}

Incarceration, Penal Abolitionism, Custodial sentences, Poverty criminalization, Penal alternatives 


\section{Movimento Abolicionista Penal}

O Abolicionismo Penal ${ }^{1}$ é uma corrente que surge a partir dos anos 1980 e seu nome é relacionado tanto a luta contra a escravidão como também contra a pena de morte, e, a partir da data supracitada, a deslegitimação do sistema carcerário e da lógica punitiva. Esta corrente busca encontrar brechas que permitam-nos perceber que a solução para cada situação-problema é única e $e_{43}$ que a redução do Estado de bem-estar social contribuiu para a promulgação das desigualdades e diminuição dos direitos sociais. Discorre sobre o poder que a linguagem possui alegando ser impossível mudar os pilares punitivos se mantivermos o vocabulário basilar que os sustentam. Por conta disso palavras como "delito" são modificadas por "situação problemática/situação-problema", isso porque o "delito" não teria em si uma realidade ontológica, ele também é um produto das políticas punitivistas que sustentam a nossa realidade social. "Os problemas são reais mas o delito é um mito. Um mito que tem consequências reais, as quais são criar novos e mais graves problemas" (Tradução livre Anitua, 2012:3).

Michel Foucault é encarado por alguns teóricos como o primeiro "abolicionista penal", embora nunca tenha se apresentado desta maneira, suas indagações a respeito das instituições totais podem ser percebidas como pioneiras das indagações a respeito das penas privativas de liberdade. Seu questionamento sobre o poder que a linguagem possui também é muito utilizado por todos os grandes nomes abolicionistas que defendem que é impossível se mudar a estrutura punitivista se mantivermos o vocabulário que a estrutura. Por conta disso palavras como "delito" são modificadas por "situação problemática", isso porque o "delito" não teria em si uma realidade ontológica, ele também é um produto das políticas punitivistas que sustentam a nossa realidade social. "Os problemas são reais mas o delito é um mito. Um mito que tem consequências reais, as quais são criar novos e mais graves problemas"3 (Tradução livre Anitua, 2012:3).

Esse posicionamento sobre mudança de vocabulário a respeito das situações problemáticas foi defendido por todos os grandes nomes fundadores do abolicionismo, Loük Hulsman, Thomas Mathiesen e Nils Christie. Os teóricos defendiam que quando a nomenclatura é modificada a percepção comum sobre aqueles problemas sociais também pode ser revista, ou seja, a sociedade não se limita mais a resposta punitivista e a comunidade pode buscar alternativas para tratar a questão.

O abolicionismo penal é caracterizado por questionar o caráter racista, higienista e segregador das instâncias punitivas. Percebe a guerra contra o suposto "crime" como uma cruzada contra os pobres, onde estes passam a responder individualmente pela violência e falta de segurança intrínsecas ao modelo de sociedade vigente. Todavia, a culpabilização dos indivíduos como mentores das ameaças a sobrevivência é imoral, visto que as principais ameaças a vida humana são a fome, concentração de terras e capital, falta de saneamento, ausência de saúde pública de qualidade, políticas geradoras de desigualdade social etc. A crença de que a violência é resultado de ações particulares para os adeptos desta corrente parece irreal (Karam, 1997: 69).

Os teóricos abolicionistas procuram defender uma prática política mais tolerante, onde se deslegitimem e sejam abolidas ideias de castigo, punição, delito, criminalidade, periculosidade, gravidade, culpabilidade, junto com as prisões. Para estes pensadores o sistema de justiça penal apenas aliena e marginaliza tanto a vítima quanto o sujeito que fora estigmatizado como criminoso, isso faz parte das estratégias de controle social que, segundo os mesmos,precisam ser deslegitimadas. "O sistema penal em todo o seu conjunto cumpre uma função modeladora para com pautas e condutas determinas, em um contexto de controle social mais amplo, a fim de disciplinar o comportamento humano em sociedade" ${ }^{\prime 4}$ (Tradução livre. Alagia \& Ciafardini, 1988: 10). 
Para os abolicionistas os processos de mediação, justiça restaurativa são mais exitosos na reparação da paz do que os que proporcionam castigos. Eles questionam as normas vigentes e propõe que outras sejam pensadas e colocadas em práticas, "normas não são, elas se tornam" (Christie, 2013:13) e isso se deve em grande parte ao fato de suas experiências individuais com regimes totalitários. Esse é um outro fator interessante desta corrente, muitos dos seus teóricos são oriundos dos países escandinavos e Holanda (o que muitas vezes gera críticas por serem países com baixa população e, por isso, com um número menor de conflitos), todavia grande parte dos autores desta corrente escreveram sobre tolerância depois de passarem pelas invasões nazistas nos seus países e após enfrentarem campos de concentração. Esta vivência da privação de liberdade durante regimes totalitários foi também impulso precursor para questionarem e criticarem os cárceres (Anitua, 2015: 697).

Essa teoria procura deslegitimar o sistema penal como um todo, desde os pilares da sua linguagem marginalizante, abolindo conceitos como "criminalidade", "delito", "criminoso" bem como permitir que se inicie uma jornada em busca de novas alternativas possíveis para se lidar com cada situação problema que surja, sejam elas pedagógicas, psicológicas, (Christie, 2013: 30) reconciliatórias, horizontais, entre outras. Por isso, os abolicionistas não pretendem criar um livro de normas como um Código Penal onde as punições para cada situação estejam previstas, justamente porque acreditam que cada caso é ímpar e deve ser tratado como tal, não existindo assim uma verdade/solução geral a ser alcançada. O objetivo em si mesmo é transcender esses modelos preexistentes, descartando classificações e criando novas metodologias para operar com o infortúnio. Então pode ser entendido como um método, que não pode se aplicar de maneira independente a realidade vigente, e que enfrenta todo o sistema de justiça penal, visto que percebe este como um problema social em si mesmo (Folter, 1988: 58-59).

A empreitada abolicionista também procura trabalhar o problema junto aos envolvidos naquela situação sem expropria-los da resolução do conflito, como é feito no atual sistema criminal, por isso destacam o papel crucial que a vítima deve ter. Para eles, não faz sentido é ineficiente o Estado resolver o conflito sem as partes interessadas uma vez que esse não conhece os envolvidos e nem passou pelas dores que este gerou. O foco deve ser em não permitir que o problema da vítima seja oneroso só a ela, mas sim que ela faça parte e atue na resolução deste da melhor forma para si. Portanto, este sistema penal alienante da atualidade só gera novos problemas e prejuízos irreparáveis aos envolvidos na situação-problemática. Como destacado por Anitua:

Um dos problemas do sistema penal é a descontextualização das situações problemáticas e sua reconstrução num contexto alheio às vítimas, aos vitimadores e aos outros indivíduos. O sistema penal cria individualidades irreais e uma interação fictícia entre eles, definindo as situações problema ou conflito de acordo com as regulamentações e as necessidades organizativas do sistema penal e de suas agências burocráticas. As partes envolvidas não põem influir em sua resolução ou continuação, uma vez que

é definido como "delito" e dele se encarregam os "especialistas" do sistema penal. O resultado disso além de não satisfazer nenhuma das partes envolvidas no problema, gera novos problemas, como a estigmatização, a marginalização social etc (Anitua, 2015: 698-699).

\section{O caso brasileiro}

Supomos que as práticas discursivas adotadas no Brasil fossem as mais voltadas para práticas abolicionistas visando a tolerância, o número de presos poderia não ter feito uma 
curva ascendente nos últimos vinte anos, uma vez que em 1990 o país contava com cerca de 90 mil presos e na atualidade esse número é superior a $726 \mathrm{mil}^{5}$. Há elementos para se crer que se o discurso abolicionista tivesse mais espaço, práticas decrescentes de encarceramento poderiam ser tomadas. Para isso se faz necessário problematizar quais aspectos foram relevantes para que a sociedade e o Estado praticassem uma espécie de obsessão punitiva, onde a prisão passa a ser entendida como solução para os problemas de violência. Isso corroborou para que o Brasil se tornasse um Estado hiperencarcerador, onde na atualidade ocupa o $3^{\circ}$ lugar ${ }^{6}$ no ranking dos países com maior população carcerária, segundo o Infopen de 2017.

Esse debate é de suma importância para a nossa conjuntura social e política, sobretudo porque é abordado distinto da narrativa predominante nos discursos criminológicos. As contribuições deste trabalho têm como prerrogativa básica a preocupação moral que temos ao integrarmos uma comunidade onde a violência faz parte da vivência afetiva diária, sendo cometida não apenas por atores externos, mas principalmente pelo Estado. A crueldade não é percebida em suas dimensões reais, a ideia do sistema prisional parece surgir para justificar a ordem através da aplicação de penas aos que cometeram infrações. Entretanto, não se dimensiona o nível insuportável e imoral de crueldade engendrada nessas unidades de aprisionamento. Buscamos gerar a sensibilidade à prisão assemelhada àquela que se produziu no século XVIII à pena de morte, apresentando elementos de como a manutenção destes espaços precisa ser revogada.

Na contemporaneidade os sujeitos que não promovem acumulação capital, não têm lugar cativo no mercado, e poderiam ser excluídos e enviados ao ambiente carcerário. Sublinharmos isso é de extrema relevância visto que Wacquant apresenta esse nicho de pessoas como os tidos woorking poor (Wacquant, 2001:21), pessoas que embora trabalhem não conseguem ascender da faixa miserável e são culpabilizados por não prosperarem socialmente numa orbe onde a não progressão econômica é encarada como falta de esforço individual e não como falta de oportunidade. Vera Malaguti no prefácio do livro de Wacquant discorre a respeito dessa postura:

Uma das perversões da nova ordem econômica é internalizar individualmente o fracasso da pobreza como responsabilidade pessoal, o que também tange a mão-de-obra no sentido de aceitar cabisbaixa o emprego precário e sem direitos (Batista in Wacquant, 2001: 9).

Como este é o mesmo público que vem durante todo o espectro da história sendo marginalizado, é imprescindível também o destaque o conceito de segregação racial e não apenas social que é um dos pilares basilares para a seletividade do controle punitivo. As teorias higienistas e práticas de embranquecimento foram fundamentais para que se criasse esse perfil falacioso de que existiria um "criminoso nato" e este teria uma predisposição genética para cometer os ditos delitos. Os conceitos de degenerescência, atavismo e eugenia legitimaram durante um longo período as violências despendidas contra esta população, uma vez que os estudos da dita criminologia científica produziram explicações patológicas e científicas para a "criminalidade".

Para isso, se fez sempre necessário questionar a suposta neutralidade científica das escolas da criminologia científica que deram a base para que práticas excludentes e autoritárias fossem engendradas ao longo dos séculos contra esta mesma população. Se faz preciso politizar a questão criminal abandonando o paradigma etiológico ${ }^{7}$ que cria a noção de um determinismo biológico para o perfil do delinquente. E é justamente a ruptura com este paradigma que se impõe para que se possa desmistificar a ideia de que o isolamento do indivíduo teria função de reabilita-lo, reeduca-lo ou reintegra-lo a sociedade. 
Essa análise fora executada com o propósito de expormos como o isolamento dos indivíduos nunca foi capaz -ou almejou- cumprir o que prometeu - as conhecidas "ilusões re $e^{8 "}$ (ressocialização, reabilitação, reeducação, recuperação) -, pelo contrário, após o internamento os sujeitos sofrem processos de exclusão social ainda mais enérgicos e quando libertados são taxados pela sociedade como perigosos e encontram duras dificuldades para conseguir empregos formais.

Dentre os autores elucidados, Wacquant nos ajuda a apresentar como a prisão é uma instituição fora da lei. Esta que deveria respeitar as normas da sociedade para supostamente reformar os indivíduos ingressantes, está o tempo todo contra estas, realizando o fim dos direitos humanos e sociais. É uma instituição insegura e precária. Não é possível acreditar nas possibilidades re de uma sociedade que não ajuda seus mais pobres, não há como reinserir alguém depois deste viver num ambiente prisional onde foi obrigado a suspender as regras sociais que conhecia "do lado de fora" e aprender todas as que eram vigentes na prisão. Sobre os pensamentos positivistas de reabilitação, destacamos a crítica na fala de Manoel Pedro Pimentel:

\begin{abstract}
Pretender treinar um homem preso para viver em liberdade, seria o mesmo que pretender treinar um corredor, para uma corrida de 3.000 metros, fazendo com que ele ficasse na cama durante 15 dias deitado, nós 0 soltaríamos para competir; e soltaríamos para correr os 3.000 metros. A comparação é mais ou menos essa (Pimentel, 1953).
\end{abstract}

Como o sistema penal está embutido na sociedade, e por esta ser classista, hierarquizada e onde as possibilidades de ascensão social são ínfimas, o sistema punitivo apenas reproduz as práticas sociais comuns, ou seja, oprime e exclui os pobres e no momento que estes cometem qualquer ato que possa ser interpretado como "desvio" são flagrados e direcionados para o ambiente carcerário. A naturalização da punição ocorre com essa adoção do pensamento a respeito dos pobres serem "classes perigosas" aliado ao papel pedagógico que o castigo realiza na interação humana da nossa sociedade. Corroborando com isso, 0 pensamento social foi construído de maneira que a punição deve ser proporcional à gravidade do suposto desvio cometido, isso nos apresenta uma falsa noção de ordenamento (Hulsman, 2012: 46).

O Direito Penal neste sentido é apenas um espaço onde jaz a capacidade de legislar a respeito das relações de poder já preponderantes, portanto, suas diretrizes são preestabelecidas para manutenção do status quo. Dito isto, encara-se a instrumentalização da segregação social através do funcionamento das múltiplas instituições (jurídica, policial, política, social) em prol do controle das massas empobrecidas. A criminalização da pobreza passa a ser praticamente a única capacidade admissível para conduzir os conflitos gerados pelo sistema capitalista (Batista, 2002: 274).

O capitalismo contemporâneo atua boicotando a força pública ao diminuir o papel do Estado de bem estar social e em contrapartida aumenta a força do Estado coercivo. Dessa maneira os recursos do Estado social diminuem da mesma maneira que inflam os gastos do Estado com segurança, encarceramento, detenções, perseguições etc. Para se realizar a deflação do Estado social além de se diminuir a verba deste também se estimulam práticas que burocratizam os benefícios sociais a ponto de desestimular os beneficiários de requerê-las, são as chamadas práticas churning. E os serviços sociais que são mantidos neste novo Estado controlador tornam-se ferramentas para se ter a população pobre sob vigilância, dessa maneira uma série de contrapartidas são cobradas das pessoas que recebem auxílios dos governos, como ter os filhos matriculados em escolas ${ }^{9}$ (learnfare), por exemplo. Wacquant atenta para 
como o eleitorado se sente mais escutado ao ver os gastos públicos com segurança ao invés de persuadirem seus políticos a investirem em estados assistencialistas:

\begin{abstract}
Prender os pobres apresenta na verdade a imensa vantagem de ser mais "visível" pelo eleitorado; os resultados da operação são tangíveis e facilmente mensuráveis (tantos prisioneiros a mais); seus custos são pouco conhecidos e nunca submetidos a debate público, quando não são simplesmente apresentados como ganhos pelo fato de "reduzirem" o custo do crime. $O$ tratamento penal da pobreza é além disso dotado de uma carga moral positiva, enquanto a questão do "welfare" está, desde o início, manchada pela imoralidade (Wacquant, 2001: 82).
\end{abstract}

Como já visto, o abolicionismo penal não é uma corrente onde todos seus autores compartilham das mesmas perspectivas. Faz-se necessário elucidar que compartilham do viés que vislumbra pensar e propor estratégias para a resolução das situações-problema. Isso não quer dizer que as propostas devam ser seguidas à risca, como dito anteriormente, não buscam realizar um manual, mas sim fazer um esforço para galgar espaço e oportunidades de resoluções mais benéficas do que apenas criticar o Código Penal sem apresentar alternativas. Isso se mostra necessário para se abandonar de uma vez as litanias acusatórias de que o Abolicionismo Penal seria um movimento utópico. Ao ressaltar essas práticas oferecem espaço para que novas ideias não-punitivas sejam criadas e também abrem uma gama de possibilidades possíveis para a resolução de problemas. Não pretendemos abordar profundamente cada uma destas instituições ou grupos, mas sinalizar sua existência e eficácia no que se propuseram a realizar.

Os abolicionistas entendem que as práticas punitivas não ressocializam os indivíduos, pelo contrário, os dados apresentados apontam para uma reincidência de $47 \%{ }^{10}$ (Carvalho, 1997: 143; Revista Fórum, 2015) na execução de novas situações problemáticas após um indivíduo ter sofrido o cerceamento da sua liberdade no sistema prisional, e, também por isso, percebem que a lógica vigente da justiça criminal precisa ser refutada e repensada caso a caso. Dito isto, a teoria do abolicionismo penal é essencial para trabalhar nesta chave onde as alternativas viáveis para cada caso problemático são pontuais aos mesmos.

Ao se pensar as possibilidades para diminuir o cárcere, a estratégia deste trabalho é buscar exemplos que não tenham recorrido ao sistema prisional para resolução de conflitos e/ou que sejam organizações que procurem pensar fora desse rigor punitivo. Portanto, ressaltaremos aqui essas experiências e instituições afim de elucubrar alternativas abolicionistas viáveis na atualidade.

É importante enfatizar que não existe a intenção de sugerir que determinadas escolhas sejam realizadas, mas sim que existem propostas palatáveis a diminuição do cárcere, por isso as alternativas seguintes se mostram como possibilidades anticarcerárias, mesmo que muitas também sejam restritivas de direitos. Algumas destas alternativas já estão em exercício, muitas das vezes são postas em prática por juízes que entendem a piora que o tempo passado enclausurado acomete a um indivíduo, e/ou a pessoas de renda mais alta que tem possibilidades muitas das vezes maiores de defesa. São as ditas penas não privativas de liberdade. Estas podem ser penas restritivas de direitos, mas não do direito à liberdade. Estão previstas no Artigo 44 do Código Penal ${ }^{11}$, e nesse artigo estão citadas uma série de restrições a aplicação desta possibilidade. Mas uma vez que existe essa opção, as penas que não restringem a liberdade do sujeito poderiam ter uma aplicação maior do que o encarceramento, posto que a regra deveria ser a liberdade e o encarceramento a exceção.

Dito isto, colocando em prática o já previsto pelo nosso Código Penal poderíamos de antemão diminuir o número de presos significativamente adotando as penas restritivas de direitos do que às restritivas de liberdades nos casos previstos pela lei, ou seja, em situações 
que não houve grave ameaça ou violência. Nesses casos, o "tráfico de drogas" - segundo lugar nos crimes que mais encarceram homens (26\% segundo Infopen 2017 ) e primeiro nas mulheres no Brasil (62\% segundo Infopen 2017), se abordado sobre essa perspectiva diminuiria significativamente o contingente carcerário.

Todavia, o que temos acompanhado é que em grande parte dos casos não é oferecido a possibilidade de medidas alternativas pelo Ministério Público. Segundo pesquisa realizada pelo IPEA em 2015 em todos os Estados da União (exceto a Bahia) a respeito das penas alternativas, mostrava que em $90,7 \%$ dos casos não foram oferecidas nenhum tipo de transação penal para medidas alternativas à privação da liberdade para os casos previstos por lei, nem suspensão condicional do processo pelo MP, como elucidados no Art 44 do Código Penal. Isso quer dizer que as penas alternativas ${ }^{12}$ não parecem estar sendo aplicadas mesmo em casos de crimes considerados de baixa gravidade. Esse dado é de suma importância para identificarmos como a diminuição do cárcere pode ser alcançada caso coloquemos em práticas opções que já estão previstas nas nossas leis e que têm sido deixadas de lado pelo judiciário.

Outro fator que podemos destacar e também foi avaliado pelo relatório é de que as penas de prestação de serviço comunitário, apesar de não serem muito utilizadas, quando o são tem oferecido resultados mais positivos do que as demais, devido ao seu caráter pedagógico. $\mathrm{E}$, posteriormente ao seu cumprimento, muitos servidores continuam sendo voluntários nas instituições onde cumpriram a pena. Além disso, apesar do judiciário não recorrer muito as penas de medidas alternativas o saldo destas parece positivo aos olhos dos assistentes sociais e profissionais psicossociais que enxergam essas medidas como possibilidades reais de transformação na vida do réu (IPEA, 2015: 84).

O relatório do IPEA é bastante esclarecedor a respeito da não utilização das medidas alternativas pelos juízes. Para além dos critérios objetivos apresentados no Artigo 44, os juízes alegam enxergar uma série de critérios subjetivos que os fazem optar por não permitir que o réu faça uso dessas alternativas. Vale o destaque ao trecho do relatório referente a esta temática:

\begin{abstract}
Apesar de a lei prever, em caso de redução de pena, a substituição por penas alternativas para os réus acusados por tráfico de drogas, a equipe do Ipea encontrou na pesquisa vários juízes que se opõem a essa possibilidade, julgando-a inclusive inconstitucional, contrariamente ao entendimento do STF. A questão das drogas esteve presente em todas as conversas com juízes e servidores. Para essas pessoas, os entorpecentes estão por detrás até mesmo de crimes que aparentemente não se vinculam imediatamente a seu uso. Juízes explicam que a droga e o furto ligados ao tráfico são as portas de entrada para a criminalidade. No âmbito desse problema, o consumo de crack parece ser, nesse momento, a maior preocupação. Em algumas localidades, principalmente em cidades do interior, juízes incluem o consumo de álcool como elemento motivador de delitos: "A legislação brasileira é uma mãe. Até tráfico agora pode. A maioria das sentenças prolatadas aqui converte. Quando não resolve logo na suspensão condicional do processo, converte no final" (Juiz, interior) (IPEA, 2015: 63).
\end{abstract}

Referente ao tema das drogas as psicólogas dos Centros de atendimento confiam e veem resultado nos trabalhos realizados com os usuários. Isso é de extrema importância destacar visto que se trata de uma ótima alternativa a essa grande porcentagem de presos ( $29 \%$ segundo CNJ 2017 e 26\% segundo Infopen de 2017) por crime de tráfico de drogas. Segundo as profissionais, muitos réus continuam o tratamento mesmo depois do tempo prescrito pelos juízes como pena. Segundo as assistentes sociais e psicólogas seria necessário que o Tribunal não valorasse somente a opinião dos juízes, como também dos demais 
profissionais porque caso todos os envolvidos no processo de aprisionamento compreendessem melhor o trabalho realizado nos centros optariam por ele mais vezes do que aos presídios, como relata uma delas: "poucos juízes "entendem o papel do centro, se entendessem haveria muito mais [centros] e com mais estrutura. Se o judiciário entendesse o impacto do trabalho do CJT investiria nesse trabalho ao invés de em presídios" (IPEA, 2015: 85).

As conclusões do relatório exaltam que essas medidas alternativas são pouco adotadas porque se opta pela prisão cautelar como regra, baseados na suposta dificuldade em encontrar o autor do crime posteriormente. É preciso salientar o recorte de classe que há nessa afirmativa. Uma vez que autores pobres e sem moradia fixa se encontram neste argumento e os autores com moradia fixa, logo, com mais capital, não cabem nessa justificativa da justiça. Para além disso, o relatório (que realizou pesquisas tanto qualitativas como quantitativas) também conclui o que já ressaltado neste trabalho, que os juízes e promotores agem para além dos critérios objetivos, muitas das vezes baseados em "intuição", e avaliam "o jeito" dos réus. Mais um elemento que pode ser percebido como classista e racista, essa suposta avaliação de postura do sujeito. Ainda há alegações do ponto de vista moral, de que os agentes da lei preferem manter presos os que usam ou praticam tráfico de drogas por terem concepções de que a droga é "a porta de entrada para crimes maiores", mesmo que isso vá diretamente em conflito as falas de psicólogas e assistentes sociais.

Também há a rasa ideia de que não punir o indivíduo com o isolamento seria deixa-lo impune. É necessário com isso denunciar a formação inadequada destes agentes da lei uma vez que a ideia de se criar medidas alternativas à prisão veio justamente pela percepção de que o encarceramento é ineficaz. O relatório sugere a realização de cursos de formação para estes juízes e demais envolvidos no processo de encarceramento.

Outra denúncia apresentada no relatório e de grande relevância para este trabalho é o fato de mesmo nestes juizados especiais (Jecrims), a vítima continuar sem ser ouvida como deveria. Isso é um problema visto que estes processos deveriam atender principalmente as demandas da vítima nestes tribunais de mediação. Estes tribunais foram criados tanto para agilizar os processos, quanto para que a vítima pudesse fazer uma parte maior deste, sendo escutadas e tendo seu bem-estar futuro como prioridade.

Uma das menções do relatório é justamente a discussão a respeito de alternativas para desinchar o cárcere brasileiro. Em prol do direito penal mínimo, como é descrito na constituição, o relatório do IPEA sugere algumas medidas para limitar o acesso direito ao aprisionamento. Destacaremos esse trecho uma vez que aventa uma série de possibilidades que buscam a diminuição do contingente carcerário.

Na discussão de um novo Código Penal minimalista podem-se levar em conta as seguintes questões: a descriminalização máxima de condutas; a redução nos tempos de pena; a ampliação do número de crimes definidos como de menor potencial ofensivo; a ampliação das possibilidades de aplicação dos institutos de renúncia, perdão e retração do agente; a redução do impacto dos agravantes nas penas; a redução de prazos de prescrição, decadência e perempção; a ampliação das possibilidades de aplicação do perdão judicial, graça e indulto; e a redução do prazo para início da progressão penal (IPEA, 2015: 90).

Para além deste relatório existem uma série de matérias, documentos e outros relatórios que apresentam como os projetos que investem nos presos e diminuem a ociosidade destes, bem como os ajudam quando enfrentam problemas relativos a abstinência de drogas. Existem uma série de programas premiados e reconhecidos como alternativas possíveis para a diminuição da degradação dos internos, como os projetos: "De olho no futuro"13 que auxilia presos para o Exame Nacional do Ensino Médio (ENEM), projetos de remição pela leitura, 
Projeto Direito no Cárcere ${ }^{14}$ que implementa oficinas de leitura, direitos humanos, cinema, música, e defende a utilização da arte como propulsora do acesso à justiça; Cidadania dos Presos $^{15}$, que procura valorizar os direitos dos presos, entre outros.

Os resultados divulgados por estes projetos são impressionantes, mostram que os presos quando tem acesso à educação, cultura e arte tem rendimentos parecidos com os dos alunos não reclusos. Isso nos faz crer que, como destacado pela presidenta do STF Carmen Lúcia ${ }^{16}$, não faz sentido gastarmos tanto dinheiro com presos se menos seria gasto com estudantes, com isso queremos dizer que o ideal seria que estes jovens não fossem privados de suas liberdades individuais, mas sim que passassem por programas de apoio verdadeiros onde obtivessem oportunidades reais de crescimento enquanto inseridos na sociedade, ou seja, fora dos ambientes prisionais.

A illuminação destes projetos não significa que sejamos defensores da promulgação de alternativas re (reeducação, reinserção, reintegração dos presos) e da manutenção das prisões. Pelo contrário, enxergamos a urgência em diminuir o contingente carcerário, todavia, enquanto este processo é realizado acreditamos que também tem caráter emergencial a melhoria das condições de vida dos internos. Por isso, os próprios abolicionistas sugerem que a defesa de uma prática não anula a seguinte, portanto, defendem a redução dos danos causados aos detentos, de maneira a criar estratégias para que enquanto vivam reclusos sejam tratados com dignidade e reais possibilidades de vivência num ambiente higiênico, não degradante e humanitário. Todavia, tem como foco principal a denúncia dos ambientes de reclusão e a promulgação da liberdade dos internos.

Contemporâneo a escrita deste trabalho foi divulgado pelo Instituto Brasileiro de Ciências Criminais (IBCCrim) um caderno de propostas legislativas que sugere 16 medidas para o desencarceramento. Esse aponta tanto para assuntos já aventados neste trabalho como urgentes de serem modificados (lei de drogas e prisão provisória), quanto discute uma série de novas guinadas metodológicas que são necessárias para a redução do contingente carcerário brasileiro, como: alteração da validade dos mandatos de busca e apreensão e dos prazos para a investigação; analise do impacto econômico da legislação penal antes que qualquer lei dessa matéria penal seja aprovada; mudanças nos critérios para cumprimento da pena e condições de flagrante; criação do juiz de garantias, entre outros. Acredita-se que doravante a aplicação dessas medidas citadas, o contingente carcerário pudesse passar por mudanças estruturais reais e apontasse para horizontes mais próximos as condutas previstas na Constituição Federal Brasileira de 1988 e no Código Processual Penal.

A elaboração destes documentos e planos de ação bem como a criação da Frente Estadual pelo Desencarceramento no Rio de Janeiro ${ }^{17}$ parecem ser os dois grandes novos esforços no campo das ciências criminais brasileiras que visam o combate à criminalização da pobreza e ao hiperencarceramento. A FED tem como objetivos gerais: contribuir com um plano para a redução do hiperencarceramento no Estado do Rio de Janeiro tanto no âmbito do sistema prisional quanto no socioeducativo, acolher as famílias dos detentos e os que exdetentos que sejam egressos, glutinar e promover pesquisas sobre esta área, acompanhar as políticas públicas estaduais referentes a este tema, principalmente as veiculadas as prisões provisórias e medidas alternativas penais, e, acompanhar as condições das prisões e unidades socioeducativas.

Essas metas visam melhorar minimamente as condições de vida dos internos bem como exigir das autoridades vigentes a promulgação dos direitos humanos dentro das unidades prisionais. É necessário que frentes como essa sejam criadas para que os órgãos responsáveis sejam obrigados a cumprir com a lei e diminuam o contingente carcerário nos Estados. Uma vez que as prisões provisórias são, como já citado anteriormente, quase a metade das prisões 
no Rio de Janeiro, a ađoção đe medidas alternativas ao invés destas e a reavaliação destas aos que já estão internados já seria capaz de mudar estruturalmente o cenário fluminense. É importante ressaltar que como a FED foi criada após as chacinas nos presídios do norte brasileiro em 2017, o impulso primordial também não deixa de habitar o imaginário de que adotando novas práticas seriam capazes de impedir que uma violência deste porte acometesse os internos (e em perspectiva as suas famílias) oriundos dos cárceres do Rio de Janeiro.

\section{Considerações finais}

É indispensável que os esforços civis e judiciários se debrucem sobre os estilos não punitivos, afastando-nos da lógica do castigo, uma vez que a nosso favor temos a falta de resultados que estes modelos despóticos têm proporcionado ao longo dos séculos de repressão e açoitamentos. Acreditamos ser necessário que os ideais libertários rompam o autoritarismo para que emerjam sociedades mais flexíveis e altruístas. Destacamos a seguir passagens de autores abolicionistas Maria Lúcia Karam, Mariano Ciafardi e Mirta Bondanza do porquê é válido atentar nosso olhar por esta direção:

Estas sociedades melhores, mais justas e mais generosas, iguais, livres, tolerantes e solidárias, podem parecer e talvez, de fato, estejam muito distantes. Utopias costumam mesmo ser distantes, mas precisam sempre ser buscadas. Se parecem tão irreais, é somente porque ainda não se realizaram (Karam, 1997: 84).

A abolição do sistema penal não pode nos nossos dias entender-se mais como uma utopia. O utópico, porém, não é sinônimo de impossível. As utopias não são falácias. E mais, muitas utopias geraram as idias fundadoras de grandes projetos sociais que tiveram finalmente sua realização (Bondanza \& Ciafardi, 1989: 7).

A preocupação do presente trabalho foi apresentar como através desta estigmatização dos indivíduos menos afortunados, estes passaram a ter seus direitos reprimidos, com políticas de segurança voltadas para o controle social do medo através do processo de policização. A teoria do abolicionismo penal nos forneceu as bases para o desenvolvimento deste argumento ao iluminar como o confinamento não gera a reabilitação dos indivíduos. Nas chamadas instituições totais o público-alvo trata-se de uma população sumariamente pobre, que em sua maioria são jovens, afrodescendentes, desempregados, sem moradia fixa e com níveis de escolaridade baixos. Esse estereótipo corrobora com a temática deste trabalho que acredita que o sistema penal cria espaços para esta massa empobrecida que não é economicamente ativa: os cárceres.

Elegemos a teoria abolicionista para lidar com as inúmeras formas alternativas para a resolução de problemas que questionam a permanência unilateral da justiça criminal como única maneira para lidar com os conflitos. Dessa forma pudemos elucubrar a respeito de maneiras alternativas para lidar com os infortúnios. Para isso destacamos a problemática da expropriação dos conflitos que foi realizada pós século XIII, onde as celeumas passaram a ser resolvidas verticalmente pelas autoridades vigentes. Anteriormente a isso a história conta que os problemas eram solucionados entre os indivíduos e/ou coletivamente, ou seja, de maneira horizontal inter-humanos e não exclusivamente através do aparato estatal. Nossa preocupação também foi investigar a imoralidade e invisibilidade de um espaço em que estão sendo direcionados um número muito grande de jovens, negros e pobres buscando diminuir as sevícias passadas por estes e a abolição destas instituições como horizonte. 
Mesmo cientes de que acaso um dia estas forem abolidas novas e mais perversas formas de controle e disciplina poderão surgir, confiamos na perspectiva de que outras soluções abolicionistas aos novos artefatos se apresentarão, e que, por ora, devemos denunciar a manutenção das penas privativas de liberdade.

Este trabalho teve como objetivo abrir mais um espaço para repensarmos as formas alternativas de lidar com os conflitos. Dito isto, apontamos a teoria abolicionista para lidar com formas outras para a resolução de conflitos que questionam a permanência unilateral da justiça criminal como única configuração para lidar com os problemas. Para indagarmos a respeito do papel da justiça criminal, foi preciso realçar o destaque crucial que o capitalismo desenvolve nessa distinção de tratamento que existe entre as situações problemáticas realizadas por pobres e ricos e a diferença com que estas são tratados pelas leis, nessa via, tivemos a pretensão de desmistificar a ideia de que os menos afortunados as cometem mais por terem uma necessidade maior de fazê-lo.

O capitalismo tardio foi apresentado como o sistema econômico que utiliza o sistema penal para governar a mão de obra, ou seja, torna-se impossível desassociar o sistema punitivo do sistema de produção, logo, os processos de criminalização da pobreza são parte da luta de classes e das distintas relações de poder imbricadas nesta. A sujeição e a disciplinarização dos corpos são peças basais para que a sociedade disciplinar funcione e tenha como ferramentas as instituições totais e seus dispositivos de controle.

O modelo punitivista que opera no Brasil e a lógica do direito penal dogmático positivista tendo em vista as práticas autoritárias e violentas engendradas no nosso sistema penal, tanto na promulgação de leis mais impositivas quanto a respeito da seletividade do sistema também foram salientados. Todavia não se teve a pretensão de indiciar estas práticas,mas sim aventar que se possa criar possibilidades para se lidar com a questão penal. Para isso, fez-se uso da teoria do abolicionismo penal, onde aborda-se pensamentos que deslegitimam a pena, e ao fazê-lo descontroem a ideia de "delito", procurando trabalhar assim com cada contexto onde não exista a macro ideia de "crime" e buscamos encarar as situações problemáticas da vida e levar em consideração que estas têm seu contexto social, político e cultural.

Logo, não pretendíamos encontrar uma solução que abarque todos os problemas que envolvem o sistema penitenciário brasileiro e a justiça criminal. Pelo contrário, a proposta foi de abrirmos um caminho para que novas alternativas sejam aventadas e possibilidades pioneiras para se tratar os conflitos sejam criadas. E é intrínseco ao pensamento abolicionista como método perceber que sempre existirão novas barreiras de controle a se superar e que por isso ele precisa ratificar seu caráter inconclusivo, expansivo e mutável, como destaca Mathiesen: "A manutenção da abolição requer que haja constantemente mais coisas para se abolir, que ao olhar mais adiante existam novos objetivos para abolir e um maior prazo, que se mova constantemente em círculos cada vez mais amplos até alcançar novos campos para a abolição"18 (Tradução livre Mathiesen,1974: 211). Por enxergar as situações como únicas, almejamos costurar visões que apresentem que não é possível se fixar as soluções para os conflitos, visto que a cada situação se apresentam uma série de circunstâncias distintas. Luiz Bicca discorre sobre as conjunturas ímpares:

A posição aqui é a de que as situações são únicas e que o conhecimento de uma solução moral somente pode ser determinado em relação aquela situação particular. Por outras palavras, a ação correta depende de ou é relativa às características específicas de uma situação (Bicca, 2012: 111).

Os abolicionistas entendem que as práticas punitivas não ressocializam os indivíduos, pelo contrário, os dados apresentados apontam para uma reincidência de $47 \%{ }^{19}$ (Carvalho, 1997: 143; Revista Fórum, 2015) na execução de novas situações problemáticas após um 
indivíduo ter sofrido o cerceamento da sua liberdade no sistema prisional, e, também por isso, percebem que a lógica vigente da justiça criminal precisa ser refutada e repensada caso a caso. Dito isto, a teoria do abolicionismo penal é essencial para trabalhar nesta chave onde as alternativas viáveis para cada caso problemático são pontuais aos mesmos.

Dessa maneira este trabalho tem o esforço de refutar as ideias reformistas sobre a prisão e maximizar o olhar sobre a imoralidade presente na manutenção dessas instituições, buscando, dessa maneira salientar que é preciso que se busque alternativas as práticas de privação da liberdade tão naturalizadas na conjuntura política vigente. Como destaca Wacquant:

O verdadeiro desafio, no caso, não é o de melhorar as condições de detenção, mesmo sendo evidentemente uma necessidade urgente, mas esvaziar rapidamente as prisões implementando uma política voluntarista de desencarceramento através do desenvolvimento de penas alternativas à privação da liberdade. Pois se não sabemos bem por que se encarcera, sabemos, ao contrário, muito bem que a passagem pela prisão exerce efeitos destruidores e desestruturantes tanto sobre os internos como sobre os seus próximos (Wacquant,2007: 144).

Parece primordial questionar esse caráter engessado que o Direito Penal ganhou na sociedade atribuindo a este todos os problemas que lhes são oriundos e apresentando como há a previsibilidade dos seus fracassos visto que estes se acumulam ao longo dos últimos dois séculos com o advento das prisões modernas. Não parece valer a manutenção da tradição prisional unicamente por falta de vontade em inventar e/ou colocar em prática novas ideias e maneiras de se lidar com as situações-problemáticas. Novas maneiras mais horizontais de se lidar com os conflitos podem ser almejadas que sejam mais pedagógicas do que os castigos perpetuados cujos resultados tem encontrado sucessivos fracassos. Como descrevia Cohen ${ }^{20}$ : "Nunca existiram grandes transformações sociais na história da humanidade que não tivessem sido consideradas utópicas ou irreais pela maioria dos expertos somente um pouco antes de quando este impensável se tornasse realidade" (Cohen, 1988:17 - tradução livre).

Portanto, propor uma agenda abolicionista penal não se funda em argumentos utópicos, mas sim em uma estrutura pedagógica que visa a conciliação através de múltiplas práticas de mediação. Estas práticas visam problematizar a sociabilidade autoritária que assujeita os indivíduos às instituições de maneira hierárquica, retirando-Ihes o papel de protagonistas das suas próprias situações-problemas, buscando elucidar que não existe uma realidade ontológica do crime, por isso, estes podem ser resolvidos no contexto social em que estão inseridos.

(Recebido para publicação em fevereiro de 2018)

(Reapresentado em julho de 2018)

(Aprovado para publicação em dezembro de 2018) 
Tamires Maria Alves

\section{Cite este Artigo}

ALVES, Tamires Maria. Pódio Vexatório: o bronze brasileiro no ranking mundial de países com maior população carcerária e as possíveis estratégias desencarceradoras. Revista Estudos Políticos: a publicação semestral do Laboratório de Estudos Hum(e)anos (UFF). Rio de Janeiro, Vol. 9 |N.2, pp. 42 - 58, dezembro de 2018. Disponível em: http://revistaestudospoliticos.com/

\section{Notas}

1. Corrente que surge a partir dos anos 1980 e seu nome é relacionado tanto a luta contra a escravidão de pessoas escravizadas, também contra a pena de morte e a partir da data supracitada, a deslegitimação do sistema carcerário e da lógica punitivista.

2. "Los problemas son reales pero el delito es um mito. Um mito que tiene consecuencias reales, las cuales son las de crear nuevos y más graves problemas" (Anitua, 2012: 3).

3. Apenas do ponto de vista conceitual, do ponto de vista da lógica da articulação política, que entendemos o populismo como "despido de conteúdo". Quando essa lógica articulatória se realiza em determinada formação social, o populismo passa a ter um conteúdo, pode ser de esquerda ou de direita, por exemplo.

4. "El sistema penal em su conjunto cumple uma función modeladora hacia pautas de conductas determinadas, em um contexto de control social más amplio, a fin de disciplinar el comportamento humano em sociedade" (Alagia \& Ciafardini, 1988: 10).

5. Fonte:http://dados.mj.gov.br/dataset/infopenlevantamento-nacional-de-informacoes-penitenciarias

6. Fonte: http://s.conjur.com.br/dl/censo-carcerario.pdf

7. Este defende que existiria uma concepção patológica da criminalidade, ou seja, determinadas causas biológicas, psicológicas e sociais gerariam o criminoso.

8. Terminologia utilizada pela professora Vera Malaguti Batista para discorrer a respeito da narrativa positivista que argumenta que os espaços de internação realizariam nas identidades dos sujeitos uma série de mudanças que os tornariam aptos depois do tempo isolados a voltar a conviver em sociedade.

9. No Brasil o programa social bolsa família obriga os pais a manterem a assiduidade dos filhos na escola.

10. Fonte:http://www.revistaforum.com.br/blog/2015/06/ani stia-internacional-por-que-a-reducao-da-maioridadepenal-e-um-retrocessp/

11. Art. 44. As penas restritivas de direitos são autônomas e substituem 
Tamires Maria Alves

as privativas de liberdade, quando: I - aplicada pena privativa de liberdade não superior a quatro anos e o crime não for cometido com violência ou grave ameaça à pessoa ou, qualquer que seja a pena aplicada, se o crime for culposo; II - o réu não for reincidente em crime doloso;

III - a culpabilidade, os antecedentes, a conduta social e a personalidade do condenado, bem como os motivos e as circunstâncias indicarem que essa substituição seja suficiente. § 1o (VETADO)

§ $2 \underline{0}$ Na condenação igual ou inferior a um ano, a substituição pode ser feita por multa ou por uma pena restritiva de direitos; se superior a um ano, a pena privativa de liberdade pode ser substituída por uma pena restritiva de direitos e multa ou por duas

restritivas

de

direitos.

§ 30 Se o condenado for reincidente, o juiz poderá aplicar a substituição, desde que, em face de condenação anterior, a medida 39

seja socialmente recomendável e a reincidência não se tenha operado em virtude da prática do mesmo crime.

$\S 4 \underline{0}$ A pena restritiva de direitos converte-se em privativa de liberdade quando ocorrer o descumprimento injustificado da restrição imposta. No cálculo da pena privativa de liberdade a executar será deduzido o tempo cumprido da pena restritiva de direitos, respeitado o saldo mínimo de trinta dias de detenção ou reclusão.

§ $5 \underline{o}$ Sobrevindo condenação a pena privativa de liberdade, por outro crime, o juiz da execução penal decidirá sobre a conversão, podendo deixar de aplicá-la se for possível ao condenado cumprir a pena substitutiva anterior.

12. Por exemplo: prestação pecuniária, perda de bens e valores, prestação de serviços, interdição de direitos, limitação de final de semana, admoestação verbal, comparecimento obrigatório a uma atividade e pagamento de cestas básicas, entre outras.

13. Relatório "Para Além das grades": Aspectos Intervencionistas da Execução Penal. Disponível em:http://www.justica.gov.br/seusdireitos/politica-penal/sistema-penitenciario-federal-1/tratamentopenitenciario/tratamento

14. Página do projeto Direito no Cárcere: https://www.facebook.com/pg/DireitonoCarcere/about/?ref=page_int ernal e http://direitonocarcere.blogspot.com.br

15. Projeto da CJ Cidadania dos Presos: http://www.cnj.jus.br/sistemacarcerario-e-execucao-penal/cidadania-nos-presidios

16. Carmen Lúcia, afirmou em 2017 como o Brasil fez as escolhas erradas em construir poucas escolas porque hoje tem de lidar com problemas de superlotação de presídios. Carmen Lúcia apontou ainda pro fato de que um preso custa mais do que um estudante de ensino médio, fato alarmante do descaso do país com os investimentos na educação. 
Tamires Maria Alves

17. Criada no dia 26 de janeiro de 2017 após as chacinas realizadas nos presídios do Amazonas, Roraima e Rio Grande do Norte em janeiro de 2017. A Frente Estadual pelo Desencarceramento é composta por movimentos sociais, organizações da sociedade civil e centros de pesquisa.

18. "El mantenimiento de la abolición requiere que haya constantemente más cosas que abolir, que al mirar hacia adelante haya nuevos objetivos para abolir a um mayor plazo, que se mueva constantemente em círculos cada vez más amplios hacia nuevos campos para la abolición"

19. Fonte:http://www.revistaforum.com.br/blog/2015/06/anistiainternacional-por-que-a-reducao-da-maioridade-penal-e-umretrocessp/

20. "Nunca há habido grandes transformaciones sociales em la historia de la humanidade que no hayan sido consideradas utópicas o irreales por la mayoria de los expertos aún pocos años antes de que lo impensable se convirtiera em realidad" (Cohen, 1988: 17).

\section{Bibliografia}

Alagia, A. (2013). Hacer Sufrir. Buenos Aires: Ediar.

Alagia, A., De Luca, J., \& Slokar, A. (2012). Derecho Penal: alternativas a la prisión. Buenos Aires.

Anitua, G. I. (2015). História dos pensamentos criminológicos. Rio de Janeiro: Revan.

Baratta, A. (2014). Criminologia Crítica e Crítica do Direito Penal. Rio de Janeiro: Revan.

Batista, N. (2002). Mídia e sistema penal no capitalismo tardio. Em Discursos sediciosos - Crime Direito e Sociedade no 12 (pp. 271288). Rio de Janeiro: Revan.

Bicca, L. (2012). Ceticismo e relativismo. Rio de Janeiro: 7letras.

Carvalho, P. A. (1997). O sentido utópico do abolicionismo penal. Em Conversações abolicionistas: uma crítica do sistema penal e da sociedade punitiva (pp. 139-154). São Paulo: IBCCrim.

Christie, N. (2013). Uma razoável quantidade de crime. Rio de Janeiro: Instituto Carioca de Criminologia.

Ciafardini, M. A., \& Bondanza, M. (1989). Abolicionismo Penal. Buenos Aires: EDIAR.

Foucault, M. (1977). A história da sexualidade $I$ - $A$ vontade de saber. Rio de janeiro: Edições do Graal.

Foucault, M. (1983). Vigiar e Punir: História da violência nas prisões. Petrópolis: Vozes.

Foucault, M. (2014). História da loucura. São Paulo: Perspectiva.

Instituto de Pesquisa Aplicada. (2015). Relatório Reincidência Criminal no Brasil. Fonte:

Comissão Nacional de Justiça: 
Tamires Maria Alves

65cd62b4e.pdf

Karam, M. L. (1997). Utopia Transformadora e Abolição do Sistema Penal. Em Conversações abolicionistas: uma crítica do sistema penal e da sociedade punitiva (pp. 67-84). São Paulo: IBCCRIM.

Mathiesen, T. (2003). Juicio a la prision. Buenos Aires: EDIAR.

Molina, A. G.-P., \& Gomes, L. F. (1997). Criminologia - Introdução e Seus Fundamentos. São Paulo.

Passeti, E., \& Silva, R. B. (1997). Conversações Abolicionistas: uma crítica do sistema penal e da sociedade punitiva. São Paulo: IBCCrim.

Passeti, E. (2004). Curso livre de abolicionismo penal. Rio de Janeiro: Revan.

Pimentel, M. P. (1953). Visão do Sistema Penitenciário Paulista, à luz da penologia moderna. Revista Jurídica.

Pimentel, M. P. (1978). Prisões Fechadas Prisões Abertas. São Paulo: Cortez \& Moraes.

Postay, M. E. (2012). El abolicionismo penal en América Latina. Buenos Aires: Editores del Puerto.

Wacquant, L. (1999). As prisões da Miséria. Rio de Janeiro: Jorge Zahar.

Wacquant, L. (09 de 08 de 2010). Class, race $\&$ hyperincarceration in revanchist America. Daedalus Summer, pp. 74-90.

Wacquant, L. (18 de 06 de 2016). Guetos e antiguetos: o novo regime da marginalidade urbana no século 21 . A Folha de São Paulo.

Zaffaroni, E. R. (1991). Em busca das penas perdidas. Rio de Janeiro: Revan. 